\title{
Optimization of Culture Conditions for Exopolysaccharide Production by a Probiotic Strain of Lactobacillus rhamnosus E/N
}

\author{
MAGDALENA POLAK-BERECKA ${ }^{1 *}$, ADAM WAŚKO ${ }^{1,2}$ and AGNIESZKA KUBIK-KOMAR ${ }^{3}$ \\ ${ }^{1}$ Department of Biotechnology, Human Nutrition and Science of Food Commodities \\ University of Life Sciences in Lublin, Lublin, Poland \\ ${ }^{2}$ Institute of Agrophysies, Polish Academy od Sciences, Lublin, Poland \\ ${ }^{3}$ Department of Applied Mathematics and Computer Science, University of Life Sciences in Lublin \\ Lublin, Poland
}

Submitted 11 October 2013, revised 3 January 2014, accepted 17 April 2014

\begin{abstract}
The effects of culture conditions on exopolysaccharides (EPS) production by a probiotic Lb.rhamnosus E/N have been studied using the Plackett-Burman design. Process optimization was performed in stationary cultures to maximize the production of EPS. In order to verify the optimal conditions, an analysis was performed of EPS production in fermentation culture. Batch fermentation was carried out at working volume of $2.5 \mathrm{l}$. The optimal temperature, $\mathrm{pH}$, carbon source, and nitrogen source conditions were $37^{\circ} \mathrm{C}$, $\mathrm{pH} 5.0$, galactose, and yeast extract, respectively. EPS production was improved by $210.28 \mathrm{mg} / \mathrm{l}$ in stationary cultures compared to $134.2 \mathrm{mg} / \mathrm{l}$ in a control grown on commercial MRS medium. The fermentor experiment showed the possibility of increasing EPS biosynthesis by $175.8 \%$. Our results clearly demonstrate that in the case of Lb.rhamnosus E/N specific culture conditions can enhance EPS production for possible application in the industry.
\end{abstract}

Key words: Lactobacillus rhamnosus, exopolysaccharide, Plackett-Burman design

Exopolysaccharides (EPS), one of the primary metabolic products of food-grade lactic acid bacteria (LAB) with GRAS (Generally Recognized as Safe) status, are an important source of natural alternatives to commercial additives of plant and animal origin. Because a greater part of those additives are chemically modified to improve their structure and the rheological properties of the product, they are not allowed in most European Union countries (Gibson and Roberfroid, 1995; Tomb and Harding, 1998). By contrast, the use of LAB producing EPS could result in safe, natural products which could be widely applied in the industry. Such products (e.g., fermented milk products) would not only be characterized by improved physical characteristics (e.g. stability and mouth-feel) (De Vuyst and Degeest, 1999) but would also have health-promoting properties since EPS produced by LAB have various beneficial physiological effects on humans, such as antiulcer action (Nagaoka et al., 1994), modulation of the immune response (Kitazawa et al., 1998), and improvement of intestinal adhesion of probiotics (Ouwehand et al., 1999). Unfortunately, so far commercial use of EPS has been limited by low production levels dur- ing fermentation (Torino et al., 2000). EPS production largely depends on culture conditions (Kimmel and Roberts, 1998; Degeest and De Vuyst, 1999; Grobben et al., 2000; Macedo et al., 2002). Usually, an excess of carbohydrates in combination with nutrient (e.g., nitrogen) limitation, stimulates EPS production (Sutherland, 1990). The effect of nitrogen on EPS production by LAB has not been examined in detail in papers published to date, but our preliminary studies indicate that limiting of the concentration of a nitrogen source in the growth medium does not decrease EPS yield (data not published). Medium constituents and other critical variables responsible for the production of biomolecules can be optimized using statistical experimental design (Chaari et al., 2012; Dominguez etal., 2012; Raza et al., 2012). Until now, however, there have been no reports on the statistical optimization of culture conditions for the production of EPS by Lb. rhamnosus strains.

In the present study, an attempt was made to optimize the production of exopolysaccharides by a probiotic Lb. rhamnosus E/N using Plackett-Burman design. Process optimization was performed to maximize the

\footnotetext{
* Corresponding author: M. Polak-Berecka, Department of Biotechnology, Human Nutrition and Science of Food Commodities, University of Life Sciences in Lublin, Skromna 8, 20-704 Lublin, Poland; phone: +48 814623 356; fax +48 81 46 23 400; e-mail: 3mj@wp.pl
} 
Table I

Plackett-Burman design for seven variables

\begin{tabular}{|c|c|c|c|c|c|c|c|c|}
\hline Run & Glucose & Lactose & Galactose & Yeast extract & Pepton K & Meat extract & Temperature & EPS (mg/l) \\
\hline 1 & -1 & -1 & -1 & 1 & 1 & 1 & -1 & 87.33 \\
\hline 2 & 1 & -1 & -1 & -1 & -1 & 1 & 1 & 42.90 \\
\hline 3 & -1 & 1 & -1 & -1 & 1 & -1 & 1 & 34.32 \\
\hline 4 & 1 & 1 & -1 & 1 & -1 & -1 & -1 & 111.32 \\
\hline 5 & -1 & -1 & 1 & 1 & -1 & -1 & 1 & 210.28 \\
\hline 6 & 1 & -1 & 1 & -1 & 1 & -1 & -1 & 18.80 \\
\hline 7 & -1 & 1 & 1 & -1 & -1 & 1 & -1 & 74.88 \\
\hline 8 & 1 & 1 & 1 & 1 & 1 & 1 & 1 & 237.12 \\
\hline & $-1=0 \mathrm{~g} / \mathrm{l}$ & $-1=0 \mathrm{~g} / \mathrm{l}$ & $-1=0 \mathrm{~g} / \mathrm{l}$ & $-1=0 \mathrm{~g} / 1$ & $-1=0 \mathrm{~g} / 1$ & $-1=0 \mathrm{~g} / 1$ & $-1=30^{\circ} \mathrm{C}$ & \\
& $1=20 \mathrm{~g} / 1$ & $1=20 \mathrm{~g} / \mathrm{l}$ & $1=20 \mathrm{~g} / 1$ & $1=10 \mathrm{~g} / 1$ & $1=10 \mathrm{~g} / 1$ & $1=10 \mathrm{~g} / 1$ & $1=37^{\circ} \mathrm{C}$ & \\
\hline
\end{tabular}

production of EPS. For verification, an analysis of EPS production in fermentation culture was performed.

Lactobacillus rhamnosus $\mathrm{E} / \mathrm{N}$, one of the components of Lakcid ${ }^{\oplus}$, a pharmaceutical product containing viable probiotic bacteria, was obtained from Biomed Serum and Vaccine Production Plant Ltd., Lublin, Poland. The strain is deposited at the Institute of Biochemistry and Biophysics of the Polish Academy of Sciences under number 2594. The bacteria were stored at $-80^{\circ} \mathrm{C}$ in MRS (de Man et al., 1060) medium supplemented with $20 \%(\mathrm{v} / \mathrm{v})$ of glycerol and were revitalized for $24 \mathrm{~h}$ in MRS broth at $37^{\circ} \mathrm{C}$ before use.

The influence of the following sources of carbon on the production of EPS by Lb. rhamnosus E/N was tested in one-factor-at-a-time experiments: glucose, galactose, fructose, lactose, sucrose, and maltose. All the saccharides were purchased from POCH, Warsaw, Poland. MRS medium containing each carbon source separately at a concentration of $20 \mathrm{~g} / \mathrm{l}$ and $\mathrm{pH} 6.3$ was distributed into flasks at a volume of $100 \mathrm{ml}$ and sterilized at $121^{\circ} \mathrm{C}$ for $15 \mathrm{~min}$. The effect of the optimal concentration of a complex nitrogen sources was examined in modified MRS broth in which yeast extract, meat extract, and peptone K (BTL, Poland) were used at different concentrations. The effect of temperature and $\mathrm{pH}$ on EPS production was also investigated in bioreactor conditions.

A revitalized culture of $L$. rhamnosus $\mathrm{E} / \mathrm{N}$ was used to prepare 24-h inocula in MRS medium, $\mathrm{pH} 6.3 \pm 0.1$. Each kind of medium in flasks was inoculated with bacteria at a concentration of $2.5 \%(\mathrm{v} / \mathrm{v})$, and the cultures were incubated at 37 or $30^{\circ} \mathrm{C}$ for $72 \mathrm{~h}$ in relatively anaerobic conditions.

Plackett-Burmann design is a very useful tool which makes it possible to screen $n$ variables using only $n+1$ experiments (Macedo et al., 2002). In the present study, it was applied to evaluate the relative importance of various nutrients for biomass production (Ghanem et al., 2000) and to limit their number. The effect of seven variables (nutrients and growth conditions) on the production of EPS by Lb. rhamnosus $\mathrm{E} / \mathrm{N}$ was studied. Each variable was tested at two levels, namely, a high level denoted by (1) and a low level denoted by $(-1)$ as shown in Table I. All experiments were conducted in triplicate, and the average value of EPS yield was used for statistical analysis.

In order to verify the optimized factors, batch fermentation experiments were performed at 2.51 working volumes using the optimal culture conditions obtained from the lab-scale tests. Lb. rhamnosus $\mathrm{E} / \mathrm{N}$ was cultivated in a 5-L fermentor (Biostat, Sartorius, Goettingen, Germany). The fermentor was controlled automatically for temperature, at $37^{\circ} \mathrm{C} ; \mathrm{pH}$, at a constant value of 6.3 or 5.0; and stirring, at $25 \mathrm{rpm}$, to keep the fermentation broth homogeneous. Fermentation was carried out for $72 \mathrm{~h}$.

After incubation, the cultures were heated at $100^{\circ} \mathrm{C}$ for $15 \mathrm{~min}$, and the cells were removed by centrifugation $(4,000 \times g, 30 \mathrm{~min}, \mathrm{rt})$. To reduce the volumes, the supernatants were evaporated using a vacuum rotary evaporator (Büchi R210: $0.093 \mathrm{MPa}, 40^{\circ} \mathrm{C}$ ). EPS were precipitated by adding three volumes of chilled $96 \%$ ethanol. The precipitating mixtures were left for $24 \mathrm{~h}$ at $4^{\circ} \mathrm{C}$. EPS were collected by centrifugation at $20,000 \times g$ for $30 \mathrm{~min}$ at $4^{\circ} \mathrm{C}$, dissolved in distilled water, and dialyzed (4,000 Da molecular weight cutoff membranes, Roth, Karlsruhe, Germany) against distilled water for $48 \mathrm{~h}$ at $4^{\circ} \mathrm{C}$. The water was changed twice. Crude freeze-dried EPS were purified by dissolving in 15\% trichloroacetic acid (TCA), and the protein precipitates were removed by centrifugation $(20,000 \times g)$. Purified EPS were exhaustively dialyzed and, finally, lyophilized. Samples were frozen at $-80^{\circ} \mathrm{C}$ for one hour and then freeze-dried in a freeze-dryer (Labconco, Kansas City, USA) at $-50^{\circ} \mathrm{C}$ and $0.024 \mathrm{mBar}$ for $18 \mathrm{~h}$.

EPS production was determined by measuring protein and carbohydrate concentrations using colorimetric methods. The total sugar content was determined by the method of Dubois et al. (1956) with glucose used as 


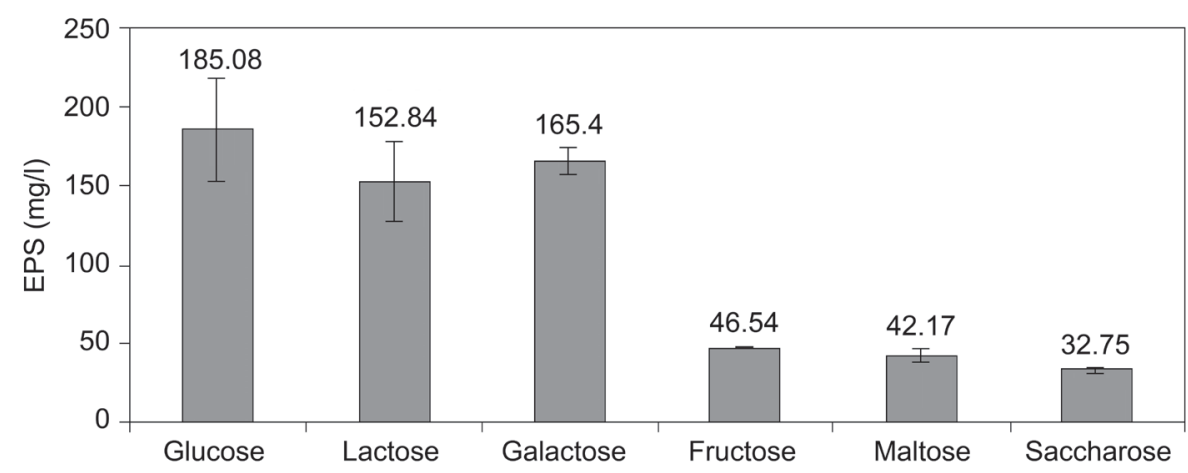

Fig. 1. Effect of various carbon sources at a concentration of $20 \mathrm{~g} / \mathrm{l}$ on exopolysaccharide production by Lactobacillus rhamnosus $\mathrm{E} / \mathrm{N}$.

a standard. Protein concentrations were estimated using the Bradford Assay Kit (Bradford, 1976).

In order to exclude contamination of EPS by sugars derived from MRS medium, the same procedure was used to precipite polysaccharides from an uninoculated medium.

Different carbon sources were evaluated for their effect on EPS production by Lb. rhamnosus E/N. It was observed that the type of carbon source had a huge influence on EPS productivity. The results revealed that glucose, followed by lactose and galactose, gave maximum EPS production (Fig. 1). These sugars are used in lactic acid bacteria to form polysaccharides in the cell with use of the "housekeeping enzymes" (Welman and Maddox, 2003). Lb. rhamnosus E/N produced three times more EPS with those saccharides than with fructose, maltose, or saccharose as a sugar source. Our findings are consistent with Gamar et al. (1997), who have reported that EPS production and yield in Lb. rhamnosus cultures were influenced by the type and concentration of the carbon source. Similar conclusions have been reached for other lactobacilli. In agreement with our results, Macedo et al. (2002) and Sánchez et al. (2006) have found that EPS production by lactobacilli was higher when glucose was used as a carbon source. Degeest et al. (2001), observed that the amount of EPS produced by Lactobacillus sakei was the highest for glucose. Also Petry et al. (2000) have reported that glucose was a better substrate than lactose for high EPS production by Lb. delbrueckii subsp. bulgaricus. All these results suggests that regulation of the biosynthetic pathway of EPS may be dependent on the carbohydrate source. On the other hand, however, also galactose has been noted as a preferred carbon source for EPS production (Fukuda et al., 2010). Because there is no consistency in the reported preference for carbohydrates regarding EPS production (Torino et al., 2005), this preference seems to be strain-dependent.

Medium components such as carbon source (chosen in the first screening experiments), nitrogen source, and incubation temperature were further screened by a Plackett-Burman design consisting of eight experiments. The results of the Plackett-Burman design analysis are presented in Table I together with factor effect estimates (Fig. 2). The factors that had a profound influence on EPS production by Lb.rhamnosus $\mathrm{E} / \mathrm{N}$ were galactose, yeast extract, and incubation temperature. It was noted that EPS production increased

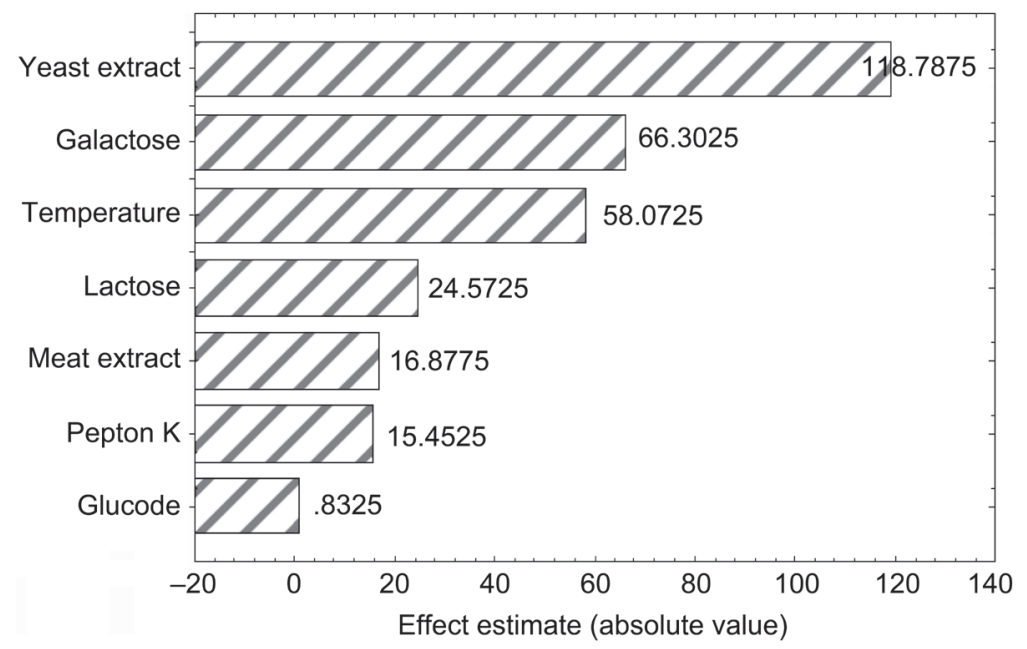

Fig. 2. Pareto chart - a ranking of variables investigated in the Plackett-Burman design. 
with an increase in the concentration of galactose and yeast extract. The production level was maximum when both of the components were added at their maximum levels. It has been shown for Lb. casei (Cerning et al., 1994) and Lb. rhamnosus (Gammar et al., 1997) that the presence of excess sugar in the medium (at concentrations between 10 and $20 \mathrm{~g} / \mathrm{l}$ ) has a stimulating effect on EPS production. Ismail and Nampoothiri (2010) have reported the highest EPS production by probiotic Lb. plantarum when the carbon source (lactose) and the nitrogen source (yeast extract) were at their maximum levels. It was shown in our experiments that yeast extract could be used to improve the production of EPS by Lb. rhamnosus $\mathrm{E} / \mathrm{N}$; this may be explain by the composition of this organic nitrogen source which includes amino acids, peptides, carbohydrates, and salts. On the negative side, yeast extract supplementation may result in contamination of EPS samples after extraction. In our study, however, contamination of EPS with carbohydrates present in yeast extract was excluded, because the EPS yields obtained were corrected by subtraction of the amounts of sugar precipitated from uninoculated MRS medium (data not shown). Because lactobacilli require various vitamins for their growth and the production of EPS (Grobben et al., 1998), yeast extract is advantageous as a source of nitrogen since it also provides vitamins and nucleic acid base components (Amrane and Pringent, 1998). Our results are in agreement with Macedo et al. (2002), who have reported that the addition of yeast extract to the production medium increased both cell growth and EPS levels in a Lb. rhamnosus culture.

The effect of temperature on EPS production by $\mathrm{Lac}$ tobacillus rhamnosus $\mathrm{E} / \mathrm{N}$ indicated that the maximum EPS yield $210.37 \mathrm{mg} / \mathrm{l}$ was obtained in cultures incubated at $37^{\circ} \mathrm{C}$ whereas in $30^{\circ} \mathrm{C}$ EPS yield was $94.66 \mathrm{mg} / \mathrm{l}$. Numerous researchers describe a direct relationship between EPS production and growth temperature in lactic acid bacteria strains (Degeest and De Vuyst, 1999; Aslim et al., 2005; Chen et al., 2006; Kim et al., 2008). Our results are similar to the results of Chen et al. (2006) and Kim et al. (2008), who have reported the highest production of EPS by Lactobacillus strains at $37^{\circ} \mathrm{C}$. In other reports, mesophilic bacteria have shown higher EPS production at temperatures equal to or lower than $30^{\circ} \mathrm{C}$ (Cerning et al., 1994; Degeest et al., 2001). These reports indicate that the optimal temperature for EPS production is dependent on the strain. Differences in optimal carbon source and incubation temperature for EPS yield highlight variations in EPS synthesis and regulation pathways in different lactobacilli. The higher production of EPS by Lactobacillus rhamnosus $\mathrm{E} / \mathrm{N}$ at $37^{\circ} \mathrm{C}$ may have been caused by the fact that this temperature was most suitable for the enzyme activity and that the metabolism rate of the polysaccharide was faster under those conditions.
Batch fermentation experiments were performed using the optimal culture conditions obtained from the Plackett-Burman design tests. The fermentation medium was modified MRS with galactose $(20 \mathrm{~g} / \mathrm{l})$ and yeast extract $(10 \mathrm{~g} / \mathrm{l})$ as the only carbon and nitrogen sources. The culture of Lactobacillus rhamnosus $\mathrm{E} / \mathrm{N}$ was run in a bioreactor at a constant temperature of $37^{\circ} \mathrm{C}$. Two $\mathrm{pH}$ values were tested: 6.3 and 5.0. Our results show that the maintenance of $\mathrm{pH}$ at a constant level is important for EPS production by L. rhamnosus $\mathrm{E} / \mathrm{N}$. The highest yield of EPS $580.38 \mathrm{mg} / \mathrm{l}$ was obtained on the optimal medium when the $\mathrm{pH}$ was maintained at the level of 5, in pH 6.3 EPS yield was $485.15 \mathrm{mg} / \mathrm{l}$. These results are in agreement with Kim et al. (2008), who have reported profound EPS production in Lb. rhamnosus ATCC 9595 at $\mathrm{pH}$ 5.5. Constant $\mathrm{pH}$ of a bioreactor culture is important as it may affect cell growth, EPS production, and uptake of different nutrients (Raza et al., 2012). The effect of $\mathrm{pH}$ on EPS production depends on the experimental conditions and the strains used. Nevertheless, it has been observed that $\mathrm{pH}$-controlled conditions have the advantage of considerably increasing EPS yield (Petry etal., 2000). For instance, Aslim et al. (2005) have reported that the amount of EPS was more than three times higher in fermentations with $\mathrm{pH}$ control than in those without $\mathrm{pH}$ control.

In conclusion, our results show that culture conditions have a clear impact on EPS production by Lb. rhamnosus $\mathrm{E} / \mathrm{N}$. The optimal temperature, $\mathrm{pH}$, carbon source, and nitrogen source conditions were $37^{\circ} \mathrm{C}, \mathrm{pH} 5.0$, galactose, and yeast extract, respectively. EPS production was improved by $210.28 \mathrm{mg} / \mathrm{l}$ in stationary cultures compared to $134.2 \mathrm{mg} / \mathrm{l}$ in a control grown on commercial MRS medium. The scale up from flask to fermentor showed the possibility of increasing EPS biosynthesis by $175.8 \%$ in commercial production processes. In batch cultures, EPS yield was $580.38 \mathrm{mg} / \mathrm{l}$, which was a relatively high value compared to those generally described for heteropolysaccharides produced by lactic acid bacteria (Petry et al., 2000; Aslim et al., 2005; Sánchez et al., 2006). So far, only three studies have been published concerning the optimization of EPS from other Lactobacillus rhamnosus strains (Gamar et al., 1997; Macedo et al., 2002; Kim et al., 2008). Our results clearly demonstrate that in the case of Lb. rhamnosus $\mathrm{E} / \mathrm{N}$ specific culture conditions can enhance EPS production for possible application in the industry.

\section{Literature}

Amrane A. and Y. Pringent. 1998. Influence of yeast extract concentration on batch cultures of Lactobacillus helveticus: Growth and production coupling. World J. Microbiol. Biotechnol. 14: 529-534. 
Aslim B., Z. Nur Yüksekdağ, Y. Beyatli and N. Mercan. 2005. Exopolysaccharide production by Lactobacillus delbrueckii subsp. bulgaricus and Streptococcus thermophilus strains under different growth conditions. World J. Microbiol. Biotechnol. 21: 673-677. Bradford M.M. 1976. A rapid and sensitive method for the quantitation of microgram quantities of protein utilizing the principle of protein-dye binding. Anal. Biochem. 72: 248-254.

Cerning J., C.M. Renard, J.F. Thibault, C. Bouillanne and M. Landon. 1994. Carbon source requirements for exopolysaccharide production by Lactobacillus casei CG11 and partial structure analysis of the polymer. Appl. Environ. Microbiol. 60: 3914-3919.

Chaari F., A. Kamoun, F. Bhiri, M. Blibech, R. Ellouze-Ghorbel and S. Ellouz-Chaabouni. 2012. Statistical optimization for the production of lichenase by a newly isolated Bacillus licheniformis UEB $\mathrm{CF}$ in solid state fermentation using pea pomace as a novel solid support. Industrial Crops and Products 40(1): 192-198.

Chen Y., L. Sun, Y. Zeng, L. Wang and L. An. 2006. The production-influencing factors of extracellular polysaccharide (EPS) from a strain of lactic acid bacteria and EPS extraction. Front. Biol. Cina 3: $236-240$.

de Man J.C., M. Rogosa and E. Sharpe. 1960. A medium for the cultivation of the lactobacilli. J. Appl. Bacteriol. 23: 130-135.

De Vuyst L. and B. Degeest. 1999. Heteropolysaccharides from lactic acid bacteria. FEMS Microbiol. Rev. 23: 152-177.

Degeest B. and L. De Vuyst. 1999. Indication that the nitrogen source influences both amount and size of exopolysaccharides produced by Streptococcus thermophilus LY03 and modeling of the bacterial growth and exopolysaccharide production in a complex medium. Appl. Environ. Microbiol. 65: 2863-2870.

Degeest B., B. Janssens and L. De Vuyst. 2001. Exopolysaccharide (EPS) biosynthesis by Lactobacillus sakei 0-1: Production kinetics, enzyme activities and EPS yields. J. Appl. Microbiol. 91: 470-477.

Dominguez A., C. Dobre, L.R. Rodrigues, A.M. Peres, D. Torres, I. Rocha, N. Lima and J. Teixeira. 2012. New improved method for fructooligosaccharides production by Aureobasidium pullulans. Carbohydrate Polymers 89(4): 1174-1179.

Dubois M., K.A. Gilles, J.K. Hamilton, P.A. Rebers and F. Smith. 1956. Colorimetric method for the determination of sugars and related substances. Anal. Chem. 28: 350-356.

Fukuda K., T. Shi, K. Nagami, F. Leo, T. Nakamura, K. Yasuda, A. Senda, H. Motoshima and T. Urashima. 2010. Effects of carbohydrate source on physiological properties of the exopolysaccharide produced by Lactobacillus fermentum TDS030603 in a chemically defined medium. Carbohydrate Polymers 79: 1040-1045.

Gamar L., K. Blondeau and J.M. Simonet. 1997. Physiological approach to extracellular polysaccharide production by Lactobacillus rhamnosus strain C83. J. Appl. Microbiol. 83: 281-287.

Ghanem N.B., H.H. Yusef and H.K. Mahrouse. 2000. Production of Aspergillus terreus xylanase in solid state cultures: application of the Plackett-Burman experimental design to evaluate nutritional requirements. Biores. Technol. 73: 113-121.

Gibson G.R. and M.B. Roberfroid. 1995. Dietary modulation of the human colonic microbiota: introducing the concept of prebiotics. J. Nutr. 124: 1401-1412.

Grobben G.J., I. Chin-Joe, V.A. Kitzen, I.C. Boels, F. Boer, J. Sikkema, M.R. Smith and J.A.M. De Bont. 1998. Enhancement of exopolysaccharide production by Lactobacillus delbrueckii subsp. bulgaricus NCFB 2772 with a simplified defined medium. Appl. Environ. Microbiol. 64: 1333-1337.
Grobben G.J., I.C. Boels, J. Sikkema, M. Smith and J.A.M. De Bont. 2000. Influence of ions on growth and production of exopolysaccharides by Lactobacillus delbrueckii ssp. bulgaricus NCFB 2772. J. Dairy Res. 67: 131-135.

Ismail B. and K.M. Nampoothiri. 2010. Production, purification and structural characterization of an exopolysaccharide produced by a probiotic Lactobacillus plantarum MTCC 9510. Arch. Microbiol. 192: 1049-1057.

Kim Y., U.K. Ji, S. Oh, J.K. Young and H.K. Sae. 2008. Technical optimization of culture conditions for the production of exopolysaccharides (EPS) by Lactobacillus rhamnosus ATCC 9595. Food Sci. Biotechnol. 17(3): 587-593.

Kimmel S.A. and R.F. Roberts. 1998. Development of a growth medium suitable for exopolysaccharide production by Lactobacillus delbrueckii ssp. bulgaricus RR. Int. J. Food Microbiol. 40: 87-92. Kitazawa H., T. Harata, J. Uemura, T. Saito, T. Kaneko and T. Itoh. 1998. Phosphate group requirement for mitogenic activation of lymphocytes by an extracellular phosphopolysaccharide from Lactobacillus delbrueckii ssp. bulgaricus. Int. J. Food Microbiol. 40: 169-175. Macedo M.G., C. Lacroix and C.P. Champagne. 2002. Combined effect of temperature and medium composition on exopolysaccharide production by Lactobacillus rhamnosus RW-9595M in a whey permeate based medium. Biotechnol. Prog. 18: 167-173.

Macedo M.G., C. Lacroix, N.J. Gardner and C.P. Champagne. 2002. Effect of medium supplementation on exopolysaccharide production by Lactobacillus rhamnosus RW-9595M in whey permeate. Int. Dairy J. 12: 419-426.

Nagaoka M., S. Hashimoto, T. Watanabe, Y. Teuro and Y. Mori. 1994. Anti-ulcer effects of lactic acid bacteria and their cell wall polysaccharides. Biol. Pharm. Bull. 17: 1012-1017.

Ouwehand A.C., V. Kirjavainen, C. Shortt and S. Salminen. 1999. Probiotics: mechanisms and established effects. Int. Dairy J. 9: 43-52. Petry S., S. Furlan, M.J. Crepeau, J. Cerning and M. Desmazeaud. 2000. Factors affecting exocellular polysaccharide production by Lactobacillus delbrueckii subsp. bulgaricus grown in a chemically defined medium. Appl. Environ. Microbiol. 66(8): 3427-3431.

Raza W., W. Yang, Y. Jun, F. Shakoor, Q. Huang and Q. Shen. 2012. Optimization and characterization of a polysaccharide produced by Pseudomonas fluorescens WR-1 and its antioxidant activity. Carbohydrate Polymers http://dx.doi.org/10.1016/j.carbpol.2012.06.021. Sánchez J.I., B. Martínez, R. Guillén, R. Jiménez-Díaz and A. Rodríguez. 2006. Culture conditions determine the balance between two different exopolysaccharides produced by Lactobacillus pentosus LPS26. Appl. Environ. Microbiol. 72(12): 7495-7502.

Sutherland I.W. 1990. Biotechnology of Microbial Exopolysaccharides. Cambridge University Press, New York.

Tomb M. and S.E. Harding. 1998. An introduction to Polysaccharide Biotechnology, pp. 185-205. Taylor and Francis, London, UK.

Torino M.I., F. Sesma and G. Font de Valez. 2000. Semidefined media for the exopolysaccharide (EPS) production by Lactobacillus helveticus ATCC 15807 and evaluation of the components interfering with the EPS quantification. Milchwissenschaft 55: 314-316. Torino M.I., E.M. Hébert, F. Mozzi and G.F. de Valdez. 2005. Growth and exopolysaccharide production by Lactobacillus helveticus ATCC 15807 in an adenine-supplemented chemically defined medium. J. Appl. Microbiol. 99: 1123-1129.

Welman A.D. and I.S. Maddox. 2003. Exopolysaccharides from lactic acid bacteria: perspectives and challenges. Trends Biotechnol. 21(6): 269-274. 
